\title{
Anaesthesia Equipment
}

\section{Patient controlled oral analgesia with morphine}

H.W. Striebel MD DEAA, M. Römer MD, A. Kopf MD, R. Schwagmeier MD
PCORA-morphine requirements were $61.5 \pm 5.2 \mathrm{mg}$ (Group I) and $52.5 \pm 8.5 \mathrm{mg}$ (Group II) (NS; mean \pm SEM). The handling of the PCORA-device presented no problem to any patient.

Conclusion: Patient controlled oral analgesia is an effective and non-invasive mode of postoperative pain management The PCORA-device is reliable and easy to use.

Objectif: Pour traiter la douleur postopératoire avec des morphiniques puissants, il est désirable d'utiliser une posologie à la demande. On présente ici un dispositif pour l'analgésie orale contrôlée par le patient (PCORA) ainsi que les premiers résultats obtenus avec une posologie de morphine orale.

Méthodes: Le dispositif PCORA était constitué d'un système de PCA Baxter (bolus maximal en volume: $0,5 \mathrm{ml}$; vitesse du débit pour réaliser le bolus: $0,5 \mathrm{ml} \cdot \mathrm{h}^{-1}$ ). Les volumes à la demande fournis par PCORA étaient mesurés à intervalles spécifiques et PCORA était comparé à la prescription antalgique habituelle (méthode CPPT). La première journée postopératoire, 20 patients orthopédiques ASA I et II recevaient aléatoirement et en croisé soit PCORA (300 min) suivi par CPPT (300 min) (groupe I) ou vice-versa (groupe II). Le dispositif $P C O R A$ permettait d'administrer une dose maximale de $15 \mathrm{mg}$ de morphine sur $60 \mathrm{~min}$ et la CPPT était administrée par un médecin ou une infirmière du service. L'intensité de la douleur (sur une échelle numérique de 101 points) et les effets secondaires étaient évalués aux $30 \mathrm{~min}$.

Résultats: La précision des volumes en bolus délivrés par le dispositif PCORA était à $89,2 \pm 0,85 \%$ (moyenne \pm SEM) des spécifications fournies par le manufacturier. Sous PCORA, l'intensité de la douleur diminuait avec le temps contrairement à la CPPT $(P<0,001)$. Sous PCORA, les besoins en morphine étaient de $61,5 \pm 5,2 \mathrm{mg}$ (groupe I) et 52,5 $\pm 8,5$ (groupe II) (NS; moyenne \pm SEM). La manipulation du dispositif de PCORA n'a posé de problèmes à aucun patient.

Conclusion: L'analgésie orale autocontrôlée par le patient représente une méthode efficace et non effractive de gestion postopératoire de la douleur. Le PCORA est fiable et facile à utiliser. 
For the management of severe postoperative pain, demand-adapted opioid titration using a device for intravenous patient controlled analgesia (PCA) is often recommended. In many countries, however, iv PCA is not used routinely and im opioid administrations still represents the standard. ${ }^{1,2}$ However, $i m$ opioid injections are invasive and do not allow titration. In several recent studies the use of intranasal fentanyl resulted in a rapid onset of action and satisfactory management of postoperative pain. ${ }^{3,4}$ Striebel et al. presented a device for patient controlled intranasal analgesia (PCINA) ${ }^{5}$ that proved to be reliable, easy to handle and safe. ${ }^{6}$ Many patients are allowed to drink and eat on the evening following the operation. Oral analgesia would be possible in these patients and is the most familiar form of drug administration. According to Moote, the oral route should be used more frequently.,8 The possibility of performing demand-adapted oral opioid titration would be ideal in these patients.

We now introduce a device for patient controlled oral analgesia (PCORA) and demonstrate the results of the first study to determine its effectiveness for postoperative pain management.

\section{Methods}

The basic elements of the device for patient controlled oral analgesia (PCORA) are supplied by the BaxterPCA-on-demand system that is used for iv PCA. This system consists of a mechanically driven infusor (balloon reservoir), a flow restrictor and a patient control module with a medication demand button for bolus administration. With the aid of a syringe, the inflatable balloon reservoir of the infusor (Figure 1) is filled with morphine via a filling port. The flow restrictor (article No. C 1073) provides a flow rate of $0.5 \mathrm{ml} \cdot \mathrm{hr}^{-1}$. The patient control module ("pain watch") (article No. C $1079 \mathrm{Q}$ ) has a bolus capacity of $0.5 \mathrm{ml}$. The opioid flows from the infusor through a kink resistant tubing, a flow restrictor and a Luer lock into the $0.5 \mathrm{ml}$ reservoir of the patient control module. By depressing the medication demand button, a bolus of $0.5 \mathrm{ml}$ is administered.

This device for iv drug titration has, with a small alteration, been adapted for patient-controlled oral analgesia. The patient control module is connected to one limb of a short plastic Y-system instead of to an iv cannula. A one-way valve is attached to the other limb of the $\mathrm{Y}$-system. The common end of the $\mathrm{Y}$-system is attached to a shortened 24-gauge plastic cannula (Figure 1). The infusor and patient control module are connected to each other to ensure user-friendly handling of the PCORA-device. The PCORA-device has a weight of about $60 \mathrm{~g}$. The total volume of the common end of

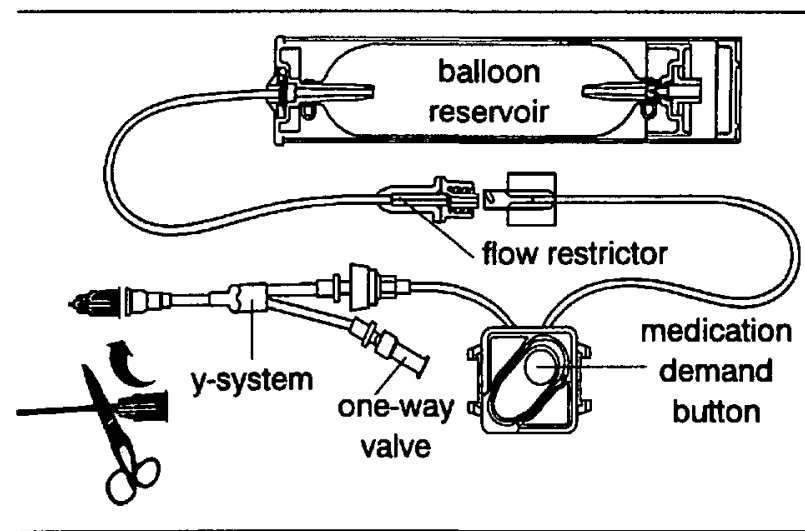

FIGURE 1 Modification of the iv Baxter PCA-on-demand system for use as an oral PCA-on-demand system.

the Y-system is slightly $>0.5 \mathrm{ml}$ so that after the demand button is depressed, the bolus volume fills this part of the system completely.

The patient empties the common portion of the $Y$ system as if drinking from a straw. Then, air fills the system through the one-way valve to ensure emptying of the system (Figure 1).

The $0.5 \mathrm{ml}$ reservoir is filled at the rate of $0.5 \mathrm{ml} \cdot \mathrm{hr}^{-1}$ within $60 \mathrm{~min}$. If the medication demand button is depressed before $60 \mathrm{~min}$, a corresponding fraction of the bolus volume of $0.5 \mathrm{ml}$ is delivered.

To verify the exactness of the delivered volume, three PCORA-devices (flow rate $0.5 \mathrm{ml} \cdot \mathrm{hr}^{-1}$ ) were examined at $10,20,30,40,50,60,80,100,200$ and $600 \mathrm{~min}$ after the last emptying of the reservoir. Each determination was repeated three times. The PCORA-device was filled with distilled water and the demanded volume was washed out from the common end of the Y-system via the one-way valve with $30 \mathrm{ml}$ air. The washed out volume was immediately weighed by means of a high precision scale (Sartorius analysis scale, Type 1712; Göttingen, Germany). The exactness of this scale is given as $\pm 0.05 \mathrm{mg}$.

After ethics committee approval and written informed consent a prospective randomized cross-over pilot study was performed to determine the effectiveness of PCORA for postoperative pain management. Exclusion criteria included present or past addiction to opioids or other medication, alcohol abuse and an allergy to opioids. Twenty orthopaedic (ASA physical status I or II) patients, 18-70 yr, were examined over $10 \mathrm{hr}$ on the day after surgery. Patients received either PCORA for five hours and then the customarily prescribed pain therapy (CPPT) for the next five hours (Group I; $n=10$ ) or they were treated initially with CPPT followed by PCORA (Group II; $n=10$ ).

The CPPT was given by the ward nurse or doctor. Using the PCORA device patients could self-administer 
a maximum of $0.5 \mathrm{ml}(15 \mathrm{mg})$ morphine $3 \%$ po per hour.

Pain intensity was evaluated using a 101-point numerical rating scale $(0=$ no pain, $100=$ the worst pain possible) at $30 \mathrm{~min}$ intervals. In addition, patients were questioned about possible side effects. At the end of the investigation period patients were questioned about the advantages and disadvantages of the pain therapy experienced and about their overall satisfaction with the two modes of pain management using a six point scale (very good, good, satisfactory, bad, very bad, not acceptable).

To analyse the intergroup differences and to compare the groups for demographic characteristics, the MannWhitney U-test was used. Differences evaluated with the verbal rating scale were analysed using the chisquare test. Time dependent changes in pain intensity were assessed by ANOVA using a two-period repeated measurements crossover design. ${ }^{9}$ The results are given as mean \pm SEM. $P<0.05$ was considered statistically significant.

\section{Results}

From the 90 measurements made from the three PCORA-devices the volume delivered was $89.2 \% \pm$ $0.85 \%$ (mean $\pm \mathrm{SEM}$ ) of the manufacturers specified value (Figure 2).

There were no intergroup differences with respect to the mean age ( 40.0 vs $47.9 \mathrm{yr}$ ), height (171.3 vs 169.5 $\mathrm{cm}$ ), weight (71.6 vs $75.3 \mathrm{~kg}$ ) or initial pain intensity (56.5 vs 50.0 on the 101-point numerical rating scale) (Group I vs Group II). The morphine dose demanded and the customarily prescribed pain therapy are shown in Table I. There were no differences between the two groups regarding the PCORA-morphine requirements.

No patient complained of nausea or vomiting. No patient experienced problems using the PCORA-device and no technical problems with the PCORA system arose.

The subjective pain intensities estimated with the 101-point numerical rating scale are demonstrated in Figure 3. There was no intergroup difference in initial pain intensity. Pain intensity with CORA decreased over time whereas with CPPT it did not $(P<0.001)$.

The PCORA was rated by patients to be superior to the CPPT $(P<0.0005)$ (Table II). At the end of the study the following advantages of PCORA were named: independence from a doctor or nurse (17/20 patients), continuous availability of analgesic ( $9 / 20)$, good analgesia (11/20), oral, painless and convenient mode of administration (4/20). Two patients complained of the bitter taste of morphine. The four patients, who received a subcutaneous injection during the period of CPPT described the painful injection as a disadvantage.

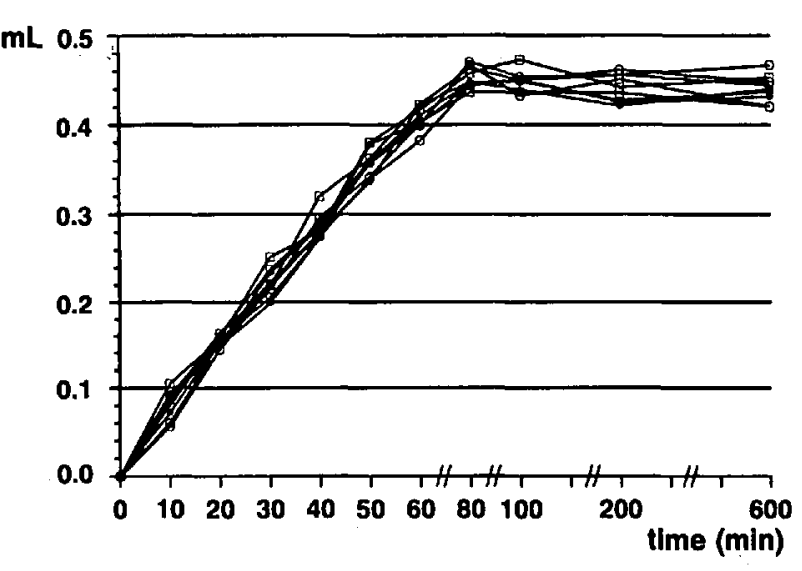

FIGURE 2 The volumes delivered at differing time intervals from the three PCORA-devices (device $1=0,2=0,3=\square$ ).

\section{Discussion}

The PCORA-device is a modification of the BaxterPCA-on-demand system. which has been found to be reliable for iv PCA. ${ }^{10-12}$ The volumes delivered by the PCORA-device and measured at specific time intervals are approximately $10 \%$ lower than the manufacturers specifications for flow rate and bolus volume. This may be because a small portion of the delivered $0.5 \mathrm{ml}$ bolus remains in the Y-system when it is washed out with $30 \mathrm{ml}$ air. The same problem may occur when the patient sips the analgesic out of the system.

As the flow rate of this device $\left(0.5 \mathrm{ml} \cdot \mathrm{hr}^{-1}\right)$ is very low, the flow restrictor incorporates a very fine capillary, that may easily be occluded by small particles, so that it is necessary to use a filter when filling the PCORA-device.

In this pilot study the clinical use of the PCORA device was investigated for the first time. The results demonstrate that patient-controlled oral morphine provides convenient and effective control of postoperative pain and is more acceptable to patients than the customarily performed pain management on this particular ward. Patients using PCORA received more medication and had lower pain scores.

The use of this device posed no problems to any of the 20 patients. The high patient acceptance experienced with $i v$ patient-controlled analgesia seems also to be true for PCORA. At the end of the study period the patients graded PCORA as better than the customarily prescribed pain therapy. As a conclusive advantage of PCORA $85 \%$ of the patients listed their independence from a doctor or nurse. These results are in agreement with a pilot study on patient controlled intranasal analgesia with fentanyl. In this study patient controlled intranasal analgesia (PCINA) was rated better 
TABLE I Drugs and dosages administered for patient controlled oral analgesia (PCORA) (mean \pm SEM) and for customarily prescribed pain therapy in both study groups. Drugs were administered subcutaneously $(s c)$ or orally.

Group l

\begin{tabular}{ll}
\hline PCORA $(0-300 \mathrm{~min})$ & $C P P T(301-600 \mathrm{~min})$ \\
\hline Morphine requirement $61.5 \pm 5.2 \mathrm{mg}$ & $\cdot 50 \mathrm{mg}$ meperidine $s c, 100 \mathrm{mg}$ tramadol, $50 \mathrm{mg}$ diclofenac, $30 \mathrm{mg}$ \\
Minimal: $30 \mathrm{mg}$ & codeine, $500 \mathrm{mg}$ acetaminophen \\
Maximal: $75 \mathrm{mg}$ & $\cdot 50 \mathrm{mg}$ meperidine $s c, 50 \mathrm{mg}$ diclofenac \\
& $\cdot 150 \mathrm{mg}$ tramadol, $50 \mathrm{mg}$ diclofenac \\
& $\cdot 500 \mathrm{mg}$ acetaminophen, $30 \mathrm{mg}$ codeine, $50 \mathrm{mg}$ diclofenac \\
& $\cdot 1000 \mathrm{mg}$ acetaminophen, $60 \mathrm{mg}$ codeine \\
& $\cdot 50 \mathrm{mg}$ diclofenac \\
& $\cdot 5 \mathrm{pts}$ no medication \\
\hline
\end{tabular}

Group 2

\begin{tabular}{ll}
\hline CPPT $(0-300 \mathrm{~min})$ & PCORA $(301-600 \mathrm{~min})$ \\
\hline - $500 \mathrm{mg}$ acetaminophen, $30 \mathrm{mg}$ codeine, $50 \mathrm{mg}$ diclofenac & Morphine requirement $52.5 \pm 8.5 \mathrm{mg}$ \\
- 2 pts $50 \mathrm{mg}$ meperidine $\mathrm{sc}, 50 \mathrm{mg}$ diclofenac & Minimum: $0 \mathrm{mg}$ \\
- $50 \mathrm{mg}$ diclofenac, $500 \mathrm{mg}$ acetaminophen, $30 \mathrm{mg}$ codeine & Maximum: $75 \mathrm{mg}$ \\
- $50 \mathrm{mg}$ tramadol, $500 \mathrm{mg}$ acetaminophen, $30 \mathrm{mg}$ codeine, $50 \mathrm{mg}$ diclofenac & \\
- $500 \mathrm{mg}$ acetaminophen, $30 \mathrm{mg}$ codeine, $50 \mathrm{mg}$ diclofenac & \\
- $50 \mathrm{mg}$ tramadol & \\
- 3 pts no medication & \\
\hline
\end{tabular}

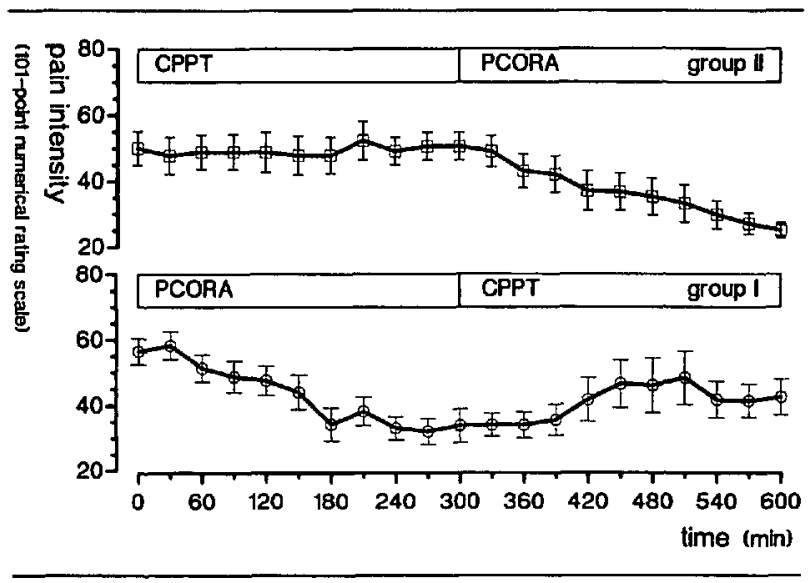

FIGURE 3 Pain intensity evaluated with the 101-point numerical rating scale in Group I $(O)$ and Group II $(\square)$; (mean \pm SEM).

$(P<0.0005)$ than customarily prescribed pain therapy and 15 of 20 patients (75\%) listed their independence from a doctor or nurse and the instant availability of pain medication as a major advantage of this PCINA. ${ }^{6}$

The onset of pain relief after PCORA is much slower than after $i v$ or intranasal opioid administration. ${ }^{6,11}$ The slower onset after PCORA is not surprising. It would therefore be ideal to start postoperative pain therapy in the recovery room with $i v$ opioid titration, to allow a rapid onset of action. Following this, PCORA could be commenced by the patient. A bolus of $15 \mathrm{mg}$ morphine was used $p o$ because, with oral administration, the high
TABLE II Patients assessment of patient controlled oral analgesia (PCORA) and the customarily prescribed pain therapy rated at the end of the study period.

\begin{tabular}{lcl}
\hline Satisfaction & After PCORA & After CPPT \\
\hline Very good & 4 & 0 \\
Good & 14 & 3 \\
Satisfactory & 2 & 9 \\
Bad & 0 & 5 \\
Very bad & 0 & 3 \\
Unacceptable & 0 & 0 \\
\hline
\end{tabular}

hepatic first pass effect must be considered. As the bioavailability of oral to intramuscular morphine is $1: 3$, an oral dose of $15 \mathrm{mg}$ corresponds to $5 \mathrm{mg}$ morphine $i m$. This single dose is low enough for titrating to effect without the risk of overdosing and respiratory depression. The dose of morphine delivered by the $0.5 \mathrm{ml}$ bolus volume of the PCORA-device can be modified by changing the concentration of morphine. In Group II, PCORA-pain intensity between the 300 and $600 \mathrm{~min}$ measurement points slowly decreased from approximately 50 to approximately 25 . When using PCORA for a longer time or when using a higher bolus dose a more pronounced decrease in pain intensity may be expected.

None of the patients demonstrated signs of respiratory depression during the PCORA period suggesting that PCORA may be as safe as iv PCA. Further studies comparing PCORA with intravenous PCA are warranted. 
We conclude that the PCORA-device is reliable, light and easy to handle and it fulfills the iv PCA-device safety requirernents. The bolus volume delivered is about $10 \%$ below the manufacturer's specifications for flow rate and bolus volume. The use of PCORA is an assessed and patient-convenient method of pain - relief that is judged by patients to be better than the customarily prescribed pain therapy. New perspectives in the management of postoperative pain may be opened with PCORA.

\section{Appendix}

Since recently, a reliable PCORA-device is available from Go Medical Industries Pty Ltd, 200 Churchill Ave, Subiaco, Western Australia 6008.

\section{References}

1 Semple F, Jackson IJB. Postoperative pain control. A survey of current practice. Anaesthesia 1991; 46: 1074-6.

2 Owen H, McMillan V, Rogowski D. Postoperative pain therapy: a survey of patients' expectations and their experiences. Pain 1990; 41: 303-7

3 Striebel HW, Koenigs D, Krämer J. Postoperative pain managenent by intranasal demand-adapted fentanyl titration. Anesthesiology 1992; 77: 281-5.

4 Striebel HW, Pommerening J, Rieger A. Intranasal fentanyl titration for postoperative pain management in an unselected population. Anaesthesia 1993; 48: 753-7.

5 Striebel HW, Römer M, Philippi W, Schwagmeier R. Ein neues Gerät zur patientenkontrollierten intranasalen Analgesie. Der Schmerz 1995; 9: 84-8.

6 Striebel HW, Oelmann T, Schwagmeier R, Brummer $G$, Rieger A. Vergleich zwischen stationsüblicher Schmerztherapie, intravenöser PCA und patientenkontrollierter intranasaler Analgesie (PCINA) im Rahmen der Therapie postoperativer Schmerzen (German). Anaesthesist 1995; 44 (Suppl 1): \$104.

7 Moote $C$. Techniques for post-op pain management in the adult. Can J Anaesth 1993; 40: R19-24.

8 Moote CA. The prevention of postoperative pain. Can J Anaesth 1.994; 41: 527-33.

9 Wallenstein S, Fisher AC. The analysis of the two-period repeated measurements crossover design with application to clinical trials. Biometrics 1977 ; 33: 261-9.

10 Irwin M, Gillespie JA, Mortón NS. Evaluation of a disposable patient-controlled analgesia device in children. $\mathrm{Br} \mathbf{J}$ Anaesth 1992; 68: 411-3.

11 Stoddart PA, Cooper A, Russell R, Reynolds F. A comparison of epidural diamorphine with intravenous patient-controlled analgesia using the Baxter infusor following Caesarean section. Anaesthesia 1993; 48: 1086-100.

12 Robinson SL, Rowbotham DJ, Mushambi M. Electronic and disposable patient-controlled analgesia systems. A comparison of the Graseby and Baxter systems after major gynaecological surgery. Anaesthesia 1992; 47: 161-3. 